\title{
Medidas administrativas con efectos expropiatorios en Colombia: el caso de los contratos de concesión minera
}

\author{
Administrative Measures with expropiatory effects in \\ Colombia: The Case of Mining Concessions
}

\author{
Lina Lorenzoni Escobar
}

\author{
Abogada \\ Universidad de Halle-Wittenberg, Alemania \\ Correo electrónico: linalorenzoni@gmail.com \\ https://orcid.org/0000-0003-3632-6603
}

\section{Resumen}

El propósito de este artículo es determinar si los derechos que derivan de un contrato de concesión minera se encuentran protegidos ante medidas estatales que vacíen de contenido las prerrogativas que otorgan dichos contratos, sin ser expropiatorias stricto sensu. Para el desarrollo de este objetivo se lleva a cabo un estudio general del concepto de propiedad privada, de derechos adquiridos y de su función social y ecológica con apoyo en la doctrina, en la jurisprudencia de la Corte Constitucional y en la del Consejo de Estado. En particular, se evidencia que dicha función social y ecológica se puede materializar mediante actos administrativos distintos a la expropiación, afectando así la propiedad privada o los derechos adquiridos. La actividad regulatoria del Estado ha incidido sobre la posibilidad de titulares mineros de ejercer los derechos derivados de un contrato de concesión minera, sin que hayan sido expropiados ni indemnizados previamente. Se concluye que el amparo de derechos derivados de un contrato de concesión minera en estos casos, implica emprender la más onerosa vía de la jurisdicción 
administrativa para que se reconozca una indemnización, lo cual atenta contra el interés general del Estado y contra los derechos del particular.

\section{Palabras clave}

Afectación, Derechos adquiridos, Derecho de propiedad, Expropiación, Contrato de concesión minera.

\section{Abstract}

The purpose of this paper is to determine whether rights that derive from a mining concession are protected when governmental measures, that are not expropriatory per se, are adopted; but that nevertheless encroach upon the rights that derive from a mining concession. To this end, this article conducts a general study of the concepts of private property, acquired rights, and their social and environmental functions, based on a review of scholarly research and the caselaw of the Corte Constitucional (Constitutional Court) and the Consejo de Estado (Council of State). In particular, this paper analyses how the social and environmental functions of property can be pursued with government measures that are not expropriations, and which thus affect private property or acquired rights indirectly. The State's regulatory activity has affected the rights that derive from mining titles, limiting the title holders' rights, without a previous formal expropriation procedure nor an indemnity. The paper concludes that the protection of these rights under Colombian law, implies, for the title holder, the costly procedure of resorting to administrative litigation to seek compensation, which goes against the general interest of the State and the rights of the title holder.

\section{Key Words}

Affectation, Acquired rights, Property Right, Expropriation, Mining Concessions.

\section{Introducción}

La protección del medio ambiente es un derecho e interés colectivo (Const., 1991, art. 88), lo que implica para el Estado la obligación de garantizarlo

\section{Cómo citar este artículo:}

Lorenzoni, L. (2020). Medidas administrativas con efectos expropiatorios en Colombia: el caso de los títulos mineros. Revista de la Facultad de Derecho y Ciencias Políticas, 50 (133), pp. 482-500. doi: http://dx.doi.org/10.18566/rfdcp.v50n133.a11

Recibido: 01 de diciembre de 2019

Aprobado: 27 de mayo de 2020 
(Sentencia T-325, 2017). Es por esto que el derecho a la propiedad privada de los particulares está supeditado a una función social y ecológica, que obedece justamente a la protección del interés colectivo de todos los colombianos. Lo anterior se desprende del Artículo 58 de la Constitución Política (Const., 1991, art. 58). Este establece la subordinación del derecho del particular a la utilidad pública o interés social, cuando estos resultaren en conflicto; se consagra además la función ecológica y social de la propiedad. Por dichos motivos de utilidad pública o de interés social, sujetos a reserva legal, podrá haber expropiación mediante sentencia judicial o por la vía administrativa, mediando en todo caso una indemnización previa.

Así, esta regulación constitucional sienta las bases para una relación complementaria y equilibrada entre propiedad y expropiación, pues no existe propiedad constitucional sin el correlativo instituto expropiatorio. En efecto, la norma constitucional ha reconfigurado la propiedad de manera que esta solo puede ser entendida en su relación con el interés general (Pimiento, 2016). Por ello, el Constituyente, al reconocer la potestad expropiatoria, fija precisas condiciones para que una expropiación sea legítima (Santaella, 2017), dichas condiciones son una garantía del derecho de propiedad. Por consiguiente, el hecho de que se prive coactivamente al particular de una propiedad legítimamente adquirida no puede calificarse como un daño antijurídico: la Constitución (1991) regula la expropiación como un actuar permitido y lícito de las autoridades (Santaella, 2017), sin perjuicio de que el sacrificio del particular expropiado sea objeto de indemnización previa. La ausencia del daño antijurídico en el supuesto expropiatorio es de particular importancia ante el interrogante que se plantea en el presente artículo. En efecto, el actuar de la administración podría materializarse no en un acto expropiatorio como el que regula el artículo 58 superior (Const., 1991, art. 58), sino en un acto administrativo que no se denomine como expropiatorio, pero con efectos equivalentes a la expropiación. Sin embargo, en estos casos, como se verá más adelante, los desarrollos legales y jurisprudenciales no prevén una indemnización previa para el particular que sufra estos efectos.

Los contratos de concesión minera son un buen ejemplo de lo anterior. A partir de 2016, Colombia ha sido notificada de sendas demandas por parte de inversionistas extranjeros, titulares mineros, en zonas del país en las que el Estado, con posterioridad a la firma del contrato de concesión minera, ha adoptado medidas de conservación ambiental. Es notorio el caso de la delimitación del Páramo de Santurbán (Resolución del Ministerio de Ambiente y Desarrollo Sostenible 2090, 2014). Esta delimitación fue dejada sin efecto 
por la Corte Constitucional ( Sentencia T-361, 2017) y aún debe realizarse nuevamente, frente a lo cual se ha pronunciado el Tribunal Administrativo de Santander para ordenar avanzar con la concertación para la delimitación (Tribunal Administrativo de Santander, 2020, Exp.680012333000-201500734-00). En el momento de la primera delimitación del páramo, por lo menos 10 títulos mineros de 28, quedaron incluidos en este (Quintero, 2014). De manera que titulares mineros, tanto nacionales como extranjeros, se vieron imposibilitados para ejercer los derechos que derivaban de sus contratos de concesión. La aprobación en 2019 por parte de la Asamblea de la Gobernación de Antioquia del Plan de Ordenamiento Departamental (POD) (2019) hará surgir situaciones similares, toda vez que el POD establece que títulos mineros que se encuentren en "áreas con potencialidad agrícola", deberán ser redelimitados (POD, 2019, art. 39). Esto afecta el alcance de los derechos derivados de situaciones jurídicas ya consolidadas, sin sentencia judicial e indemnización previas.

Es significativo que los inversionistas extranjeros acudan al arbitraje inversionista-Estado previsto en los tratados internacionales de protección a la inversión extranjera que los cobijan. En el ejemplo citado del Páramo de Santurbán, las empresas canadienses afectadas iniciaron arbitraje inversionista-Estado bajo el capítulo de inversiones del Tratado de Libre Comercio (2011) firmado con Canadá. Dicho Tratado contempla la figura denominada expropiación indirecta, que se define como un acto o una serie de actos que tienen un "efecto equivalente al de una expropiación sin la transferencia formal del título o del derecho de dominio" (TLC con Canadá, 2011, Anexo 811, Numeral 2). ¿Cuáles derechos tiene, bajo el ordenamiento colombiano, un titular minero que - sin ser expropiado - sufra efectos equivalentes debido a regulaciones ambientales?

El presente artículo aborda este interrogante a partir de una revisión doctrinaria del derecho de propiedad privada sobre los inmuebles superficiales y los derechos adquiridos sobre otros bienes y derechos, su función social y ecológica. En un segundo momento, se analizan los derechos que otorga un contrato de concesión minera, para concluir sobre su naturaleza de derecho adquirido. A partir de ahí, se mira específicamente cómo medidas administrativas semejantes a las descritas, que no son expropiatorias stricto sensu, pueden afectar el desarrollo del objeto del contrato de concesión minera con efectos similares a una expropiación, sin que el ordenamiento colombiano prevea una compensación o indemnización previa. 


\section{Derechos adquiridos y contratos de concesión minera: una aproximación desde la propiedad constitucional}

El Artículo 58 superior (Const., 1991, art. 58) evidencia una visión de la propiedad y de su régimen de protección, que se aparta de una concepción eminentemente real del derecho de propiedad para amparar posiciones jurídicas de contenido patrimonial, en las que podemos incluir los títulos mineros. En efecto, la propiedad constitucional abarca tanto la propiedad común y ordinaria, como los demás derechos patrimoniales adquiridos con arreglo a la ley (Santaella, 2017). Lo anterior se desprende del texto del Artículo 58 de la Constitución (Const., 1991, art. 58), en el que si bien se distingue la propiedad privada de los demás derechos adquiridos, su garantía constitucional es la misma (Blanco, 2018): ambos son garantizados por la Constitución y ambos ceden ante el interés público y social (Sentencia C-983, 2010). Así lo ha entendido la jurisprudencia constitucional cuando ha indicado que la expropiación comprende tres elementos característicos, siendo el objeto uno de ellos. Este objeto se describe como un derecho de índole patrimonial que es sacrificado en favor del interés general (Sentencia C-227, 2011). Ya bajo el imperio de la Constitución de 1886, el legislador contaba con amplísimas facultades para definir regímenes especiales en esta materia, abarcando así no sólo bienes inmuebles; sino bienes muebles y derechos intelectuales (Hernández, 2017). Por tanto, la propiedad constitucional se inscribe en una larga tradición en la que el acto expropiatorio podría predicarse no sólo de derechos reales; sino de derechos de contenido patrimonial.

La Corte Constitucional ha definido los derechos adquiridos como situaciones individuales y subjetivas creadas bajo el imperio de una ley, que debe ser respetada frente a leyes posteriores, las cuales no pueden afectar lo legítimamente obtenido al amparo de una ley anterior (Sentencia C-168, 1995; Sentencia C-242, 2009). Las situaciones individuales y subjetivas a las que se refiere la Corte Constitucional, se definen como derechos adquiridos, en la medida en que se hayan verificado todas las circunstancias y requisitos legales previstos para atribuir o dar por nacido un derecho, aunque este no haya sido ejercido o consumado aún (Sentencia C-168, 1995). La Corte Constitucional también distingue los derechos adquiridos de las meras expectativas que, por no haberse consolidado en un derecho, gozan de una protección más precaria (Sentencia C-242, 2009). A la luz del interrogante planteado aquí, es procedente estudiar si un contrato de concesión minera debidamente celebrado es un derecho adquirido y, por tanto, si está amparado por el Artículo 58 superior (Const., 1991, art. 58). 
Los contratos de concesión minera con el Estado se perfeccionan con su inscripción en el Registro Minero Nacional. Estos otorgan de forma excluyente al concesionario la facultad de efectuar los trabajos necesarios para establecer la existencia del depósito dentro de la zona concedida, luego aquellos que son necesarios para explotarlo (Ley 685, 2011, art. 14, 15 y 58). Si bien el Estado es propietario de los minerales que se encuentren en el suelo y en el subsuelo (Const., 1991, art. 332), en cabeza del concesionario surge un "derecho público subjetivo" de uso de ese bien público que es el subsuelo (Sentencia C-983, 2010): este derecho es de contenido patrimonial y es oponible frente a terceros (Sentencia 11001-03-26-000-2006-00052-01(33187), 2010).

Deben señalarse aquellas interpretaciones que desconocen el contrato de concesión minera como un derecho adquirido. Estas interpretaciones se basan principalmente en dos argumentos: por un lado, se indica que el régimen para la explotación de recursos naturales es de derecho público. Al no derivarse de la legislación civil, a la cual se refiere el artículo 58 de la Constitución (Const., 1991, art. 58) para describir el origen de las situaciones jurídicas consolidadas dignas de protección, no se crearían derechos adquiridos (Luna y Correa, 2015; Amaya, 2017). Esta interpretación exegética de la expresión “con arreglo a las leyes civiles” desconoce el origen histórico de la misma, que en la Constitución de 1886 se refería a situaciones subjetivas adquiridas con justo título (Const., 1886, art. 31). Esta lectura es acogida por la misma Corte Constitucional al interpretar el artículo 58 de la Constitución actual (Const., 1991, art. 58), pues se reconoce que la expresión "no es específica sino genérica, es decir, alude tanto a las reglas integrantes del Código Civil y sus disposiciones complementarias, como al conjunto del ordenamiento jurídico basado en la constitución” (Sentencia C-374, 1997). No puede asumirse una lectura literal de la norma constitucional; más bien entender que la expresión, "con arreglo a las leyes civiles” se refiere a situaciones creadas con justo título (Herrera, 2002).

El segundo argumento de quienes desconocen que el contrato de concesión minera sea un derecho adquirido considera que, al ser el título minero el fruto de una relación de derecho público, nunca se consolidaría una situación en favor del titular, puesto que esta sería siempre revocable por la autoridad. Esta posición es amparada en un pronunciamiento de la Corte Constitucional, según el cual: "en materia de derecho público, la noción de derechos adquiridos tiende a diluirse, puesta esta noción, admitida universalmente se refiere sustancialmente a los derechos que regulan las leyes civiles” (Sentencia T-001, 1992). Sin embargo, una lectura atenta de esta sentencia nos indica que la 
Corte Constitucional no necesariamente excluye los derechos adquiridos en el derecho público, pues la noción es “admitida universalmente”, lo cual debe interpretarse como un reconocimiento de que los derechos adquiridos trascienden, a la vez que incluyen, aquellos derivados de las leyes civiles. Dicho segundo argumento se sustenta también en una decisión del Consejo de Estado, en la que se afirma que actos administrativos como los "permisos, licencias, autorizaciones y similares" son provisionales, subordinados al interés público y que, por tanto, los derechos particulares nacidos de la aplicación del derecho policivo no son definitivos $\mathrm{y}$, por consiguiente, no generan derechos adquiridos (Sentencia 5500, 1999). Sin embargo, al margen de la referencia en la citada sentencia al derecho derivado del derecho policivo, el Consejo de Estado ha distinguido el título minero de otros títulos habilitantes sobre bienes de propiedad pública, al aclarar que la concesión minera no soporta el criterio de la "precariedad de los derechos otorgados”, esto significa que se limita el ius variandi de la Administración (Sentencia 11001-03-26-000-2006-00052-01(33187), 2010). Lo anterior dado que el título minero se deriva de un contrato de concesión que no está sujeto a modificaciones o terminaciones unilaterales, con excepción de la caducidad. La calificación de contrato estatal que tiene el contrato de concesión minera es el resultado de una decisión expresa del ordenamiento colombiano. Con esta se buscó justamente superar las inquietudes con respecto a las concesiones mineras como simples actos administrativos de autorización, sometidos por tanto a un régimen precario que dependía de la mera voluntad de la autoridad administrativa competente (Santos, 2016). El régimen no precario del contrato de concesión minera encuentra su sustento lógico en que se trata de una concesión demanial, que no obedece a las reglas características de la contratación pública (Santos, 2016).

Finalmente, conclusiones orientadas a desconocer que el título minero sea un derecho adquirido con base en un argumento de precariedad de la concesión, desconocen también la naturaleza del derecho de propiedad constitucional, el cual está lejos de configurar situaciones jurídicas absolutas o definitivas. Por el contrario, son estructurales al derecho de propiedad su función social y ecológica, de manera que, incluso en relaciones de "derecho civil”, podría intervenir la autoridad para encauzar el ejercicio del derecho de propiedad para lograr estas funciones. La aparición de la protección del medio ambiente ha producido un cambio sustancial en el derecho de propiedad, con regímenes altamente restrictivos de su pretendido individualismo (Pimiento, 2016). En este sentido, pronunciamientos orientados a distinguir el régimen civil del público, con base en la absoluta autonomía de la voluntad del primero y la 
precariedad del segundo, desconocen este cambio sustancial en la concepción del derecho de propiedad.

En consecuencia, debemos concluir que un contrato de concesión minera constituye un derecho adquirido del titular minero. De la propiedad pública de los minerales en el suelo y en el subsuelo se desprende, entre otros, la protección de los derechos adquiridos en cabeza de los particulares (Pimiento, 2015). La situación jurídica del concesionario minero se consolida a partir de la inscripción del acto que otorga el título minero en el Registro Minero Nacional (Ley 685, 2011, Art. 50; Sentencia C-983, 2010). El hecho de que deba tramitarse una licencia ambiental para el desarrollo de la actividad de explotación una vez concluida la fase de exploración, no obsta para que se configure un derecho adquirido desde la inscripción en el Registro Minero Nacional pues, de lo contrario, no habría seguridad jurídica alguna para las cuantiosas inversiones de la etapa exploratoria. En ese sentido, no puede interpretarse que el derecho adquirido se configure únicamente desde el otorgamiento de la licencia ambiental, es decir, desde la etapa exploratoria, máxime porque, según el Código de Minas (2001), el título minero ampara tanto la exploración como la explotación minera.

En efecto, la Corte Constitucional al interrogarse sobre la constitucionalidad del levantamiento de prohibiciones ambientales "para preservar los derechos adquiridos”, se refiere al restablecimiento de fundamentos jurídicos con base en los cuales se han entregado licencias ambientales "y/o" contratos de concesión (Sentencia C-035, 2016). Se da así a entender que en ambos casos se consolidan derechos adquiridos, no condicionando la consolidación de estos a la existencia de la licencia ambiental. Lo que ocurre es que el contenido patrimonial del derecho adquirido variará según la etapa contractual en la que se encuentre, teniendo por tanto un alcance en etapa de exploración distinto al que tiene en etapa de explotación, donde ya el depósito está probado, se está extrayendo el recurso y esto se desarrolla gracias a una licencia ambiental otorgada.

\section{II. "Pulverización" de contratos de concesión minera ante su función social y ecológica}

La Corte Constitucional ha afirmado que el interés general que existe en la protección del ambiente prevalece frente a los derechos económicos 
adquiridos por particulares mediante licencias ambientales y contratos de concesión (Sentencia C-035, 2016). Lo anterior es apenas lógico, pues son claras las funciones social y ecológica que nuestro ordenamiento da a la propiedad privada y a los derechos adquiridos o el interés general que se deriva de la protección del ambiente. En efecto, si bien la propiedad minera en Colombia, en tanto derecho adquirido, tiene características que la distinguen de la propiedad común, en ningún caso la sustraen del imperio de las normas generales de orden público económico, lo que implica que la obliga el precepto constitucional (Sarria, 1945). Por esto mismo, el precepto constitucional también ampara la propiedad minera. En otras palabras, la subordinación al interés general de proteger el ambiente y el derecho a gozar de un ambiente sano no está exenta de garantías para el titular del derecho sacrificado. El artículo 58 de la Constitución (Const., 1991, art. 58) identifica dicha garantía en la reserva legal del interés general y en la indemnización a favor del titular de un derecho que es expropiado.

Amparados por el artículo 58 de la Constitución (Const., 1991, art. 58), los contratos de concesión minera están subordinados al interés general y, por tanto, son expropiables. La expropiación no puede limitarse a un concepto real de la propiedad, más bien debe caracterizarse como "una forma de intervención estatal sobre posiciones jurídicas particulares que se legitima en la prevalencia del interés general sobre el particular” (Hernández, 2017, p. 163). Los supuestos bajo los cuales el Estado privará a un sujeto de sus posiciones jurídicas en favor de la colectividad, dependerán del momento histórico y de cómo dicho momento conceptúa los intereses más altos, susceptibles de prevalecer sobre una posición jurídica particular (Hernández, 2017). El constituyente de 1991 identificó estos intereses en el ambiente y su protección como un derecho colectivo de interés general, por lo que se previó como obligación de los particulares la función ecológica y social de sus derechos, de ahí que su incumplimiento pueda determinar incluso la extinción de tales derechos.

Lo anterior es especialmente importante pues si solo la propiedad dominical, contemplada en el artículo 669 del Código Civil (1873), fuera susceptible de ser expropiada, no sólo se dejarían por fuera de la cobertura del régimen constitucional de la propiedad numerosas e importantes posiciones jurídicosubjetivas de contenido patrimonial, como son las concesiones mineras (Santaella, 2017); sino que se dejaría por fuera la posibilidad de expropiar estas posiciones de contenido patrimonial, lo cual es un absurdo que mal se compagina con los fines sociales del Estado. En efecto, esta interpretación 
significaría que existen en el país propiedades inviolables y refractarias al interés general (Santaella, 2017). Estas estarían así sometidas al régimen más oneroso de la responsabilidad extracontractual del Estado, puesto que aquí sí se configuraría un daño antijurídico, justamente en detrimento de dicho interés general; pero también de los intereses individuales (Santaella, 2017). En este sentido, al abordar aquí la “expropiación”, se entenderá que procede tanto para propiedades reales como para derechos adquiridos, un reflejo del artículo 58 de la Constitución (Const., 1991, art. 58) que no distingue, como ya se vio, el régimen de ambas categorías de derechos.

Sin embargo, puede no existir un acto administrativo expropiatorio, sino un acto administrativo de otra índole con efectos expropiatorios. Estos últimos pueden implicar la erosión del contenido de un derecho de índole patrimonial, sin que dicho derecho vaya a engrosar el patrimonio del Estado. Si se entiende la expropiación como una herramienta para superar barreras jurídicas para la ejecución de políticas públicas (Santaella, 2017), esta no necesariamente implicará el traslado patrimonial del derecho expropiado; sino que también podrá darse mediante desaparición o “pulverización” de una determinada posición de contenido patrimonial (Santaella, 2017, p. 83). En este sentido, mediante la afectación de un derecho a un fin ecológico, el ordenamiento reconoce que no es sólo mediante la expropiación que se puede destinar un bien al interés general; sino que dichos objetivos se pueden garantizar aun cuando el bien esté en manos del particular, garantizando la titularidad; pero restringiendo el derecho de su propietario (Pimiento, 2017a). Esta concepción de la expropiación refleja más de cerca el fenómeno que se da cuando los derechos derivados de un contrato de concesión minera no pueden ejercerse debido a una actuación administrativa, como puede ser la declaración de un parque. En este caso, no media expropiación concebida como traslado patrimonial; sino una pulverización de derechos, que incluso quedan formalmente en cabeza de su titular y siguen causando obligaciones para el concesionario.

En el caso de los contrato de concesión minera, es el mismo Código de Minas (2001) el que establece la prohibición de actividades mineras en zonas declaradas y delimitadas conforme a la normatividad vigente como de protección del ambiente (Ley 685, 2011, art. 34). La exclusión opera para el otorgamiento de los contratos de concesión; pero ni el Código de Minas ni la normatividad administrativa en vigor regulan el supuesto de la delimitación del área protegida que se dé con posterioridad a la firma del contrato de concesión. Lo anterior no debería ni puede significar que el titular afectado no disponga del derecho a ser indemnizado. Incluso quienes sostienen que un título minero 
no es un derecho adquirido, afirman que no por esto pueden desampararse los derechos de los particulares, quienes también se encuentran protegidos constitucionalmente (Amaya, 2017) y que las cargas que deben soportar por esa función ecológica no son ilimitadas (Amaya, 2017).

Esta omisión se hace aún más evidente en la medida en que el ordenamiento legal y constitucional colombiano es reiterativo en amparar las posiciones de los particulares, afectadas por medidas de la autoridad, mediante una indemnización previa. Incluso en los excepcionales casos en que la afectación ocurre sin que se haya logrado acuerdo sobre el precio indemnizatorio, como en el caso de las autorizaciones temporales para el desarrollo de proyectos de infraestructura, el legislador se preocupa de regular el procedimiento mediante el cual indemnizar al titular afectado (Ley 1682, 2013, art. 59).

Por su parte, el Artículo 336 de la Constitución (Const., 1991, art. 336) dispone que la ley que establezca un monopolio debe haber indemnizado previamente y plenamente a los individuos que, en virtud de ella, quedan privados del ejercicio de una actividad económica lícita. De igual manera, el Artículo 365 Superior (Const., 1991, art. 365) establece que, si por razones de soberanía o de interés social, el Gobierno se reserva determinadas actividades estratégicas o servicios públicos, “deberá indemnizar previa y plenamente a las personas que, en virtud de dicha ley, queden privadas del ejercicio de una actividad lícita” (Const., 1991, art. 365). En ambos casos, el hecho que el Estado opte por reservarse determinadas actividades o servicios, priva a quienes los ejercían ya no de una propiedad real; sino de una posición subjetiva patrimonial concedida por el mismo Estado. Se trata pues de posiciones subjetivas similares a las que se derivan de un contrato de concesión minera, en la medida en que son fruto de una concesión estatal. En estos casos, si el Estado erosiona el derecho que había sido otorgado, la Constitución establece la indemnización previa y plena. La erosión mencionada no es una expropiación, pues en ambos casos la medida administrativa es de otra índole: el establecimiento de un monopolio, la reserva estatal de cierto tipo de actividad, por razones de interés social o estratégicas. Así, en el caso de estas posiciones subjetivas se reconoce que existen límites al ejercicio de estos derechos, así como los que establece el ordenamiento al derecho de propiedad o de los derechos adquiridos, sin que ello implique necesariamente su supresión (Pimiento, 2016), puesto que se compensa al titular afectado.

La ausencia de una disposición expresa, constitucional o legal, que permita al titular de una determinada posición subjetiva patrimonial — ya sea una 
propiedad tradicional o un derecho adquirido - ser indemnizado previamente en caso de medidas administrativas no expropiatorias que afecten su título, obliga a dichos titulares a la vía más onerosa tanto para ellos como para el Estado de la jurisdicción administrativa.

\section{Reflexiones en torno a mecanismos de resarcimiento para actos de efecto expropiatorio}

En general, la legislación colombiana sigue aferrada al concepto clásico de expropiación que deriva de la comprensión civilista del derecho de propiedad (Santaella, 2017). De manera que las leyes relacionadas con la expropiación o afectación, lo hacen con referencia a bienes inmuebles (Ley 9, 1989, art. 9 y art. 37). Lo anterior se predica también de los desarrollos jurisprudenciales, puesto que si bien el Consejo de Estado ha incursionado en el estudio de las situaciones jurídicas creadas a partir de actos administrativos con un efecto expropiatorio —a través de su teoría de la ocupación jurídica-, lo ha hecho con base en la propiedad real.

En 1992, el Consejo de Estado conoció la demanda de un propietario de un predio sobre el que se había declarado un parque natural y que solicitaba una indemnización por los perjuicios causados, tras alegar una pérdida del derecho de propiedad (Consejo de Estado, 1992, Expediente 6643). La Sección Tercera del Consejo de Estado efectivamente consideró que se había comprometido la responsabilidad patrimonial del Estado, por cuanto esa restricción del ejercicio de los derechos del propietario resultaba intolerable con respecto a la protección que el ordenamiento otorga a la propiedad (Pimiento, 2017a). De este modo, el Consejo de Estado indicó que la ocupación de un inmueble no se limita a la ocupación por obras públicas, consagrada en el entonces vigente Artículo 220 del Código de lo Contencioso Administrativo (1984); sino que un inmueble puede ocuparse también “con la prohibición absoluta del dueño de ejercer los derechos personales y reales que le corresponde sobre el inmueble de su propiedad" (Consejo de Estado, 1992, Expediente 6643). Lo anterior impone una declaratoria de responsabilidad patrimonial bajo un régimen objetivo (Pimiento, 2017), sin una valoración de las restricciones derivadas de la función social y ecológica de la propiedad (Santaella, 2013). La indemnización en este supuesto está sometida a los principios de reparación integral del daño, comprende el daño 
emergente y el lucro cesante (Sentencia 1990.10957, 2005); pero en ningún caso se trata de una indemnización previa.

En 2012, la Sección Tercera del Consejo de Estado desarrolla dicha teoría de la ocupación jurídica (Sentencia 1993-04137, 2012), para distinguir entre las afectaciones que expropian un bien, de aquellas que garantizan la titularidad del propietario, pero que restringen su derecho de propiedad (Pimiento, 2017a). En efecto, el fallo indica que las afectaciones requeridas para aplicar de preferencia el interés general encuentran sustento constitucional; no obstante, el impacto de dichas afectaciones debe analizarse mediante un juicio de proporcionalidad, bajo el entendido que se debe respetar en todo evento el "núcleo esencial" de la propiedad (Sentencia 1993-04137,2012). Esta lectura implica la transición de un modelo en el que la destinación de un bien al interés general implicaba la expropiación del mismo a un modelo en el que los objetivos constitucionales se pueden garantizar estando el bien en manos del particular (Pimiento, 2017a). En efecto, el fallo indica que existe un "abanico de posibilidades de intervención” (Sentencia 1993-04137, 2012), al ser la expropiación el de mayor intensidad; además, que tanto la expropiación como las afectaciones al interés general constituyen "especies del mismo género: la intervención del Estado en la propiedad” (Sentencia 1993-04137, 2012).

El abanico de posibilidades de intervención tiene consecuencias distintas para el propietario y para el Estado. Si la intervención es expropiatoria, serán necesarias la declaración de afectación y la iniciación de los trámites legales tendientes a la expropiación. Si, en cambio, la intervención consiste en una afectación, será necesario establecer si dicha afectación excede, o no, los límites de obligatoria tolerancia de las cargas derivadas de la función social y ecológica de la propiedad. En caso de que los exceda, se configura un daño antijurídico, ante el cual procederá la indemnización por perjuicios materiales: daño emergente y lucro cesante: "por cuanto en este evento la afectación tendrá alcance expropiatorio” ( Sentencia 1993-04137,2012). Si, por lo contrario, la afectación no excede dichos límites, se trata de una afectación que el propietario está en deber de soportar y no se considera que exista un daño antijurídico. Lo anterior porque no se vulnera el "núcleo esencial” de la propiedad, la cual es descrita por la Sección Tercera de manera ciertamente vaga, como "la posibilidad de explotar jurídicamente y económicamente el bien" (Sentencia 1993-04137, 2012). Sólo si la afectación vulnera el "núcleo esencial” del derecho de propiedad, mediante la "limitación absoluta y permanente de los derechos del propietario”, habrá lugar a aplicar la teoría de la ocupación jurídica permanente; de lo contario, al no tener alcances expropiatorios, el juez 
determinará la indemnización por los perjuicios para compensar las cargas públicas que la afectación impone ( Sentencia 1993-04137,2012).

Es la intensidad de la intervención sobre el contenido del derecho de propiedad, entonces, la que diferencia afectaciones que son ilegítimas - de alcance expropiatorio - y aquellas que son legítimas; sin embargo, a pesar de ello pueden suponer un desequilibrio en las cargas públicas, merecedor de compensación. En el primer caso, la analogía con la ocupación permanente es más clara; en el segundo, los daños por esa ruptura de la igualdad ante las cargas públicas se basan en la teoría del daño especial (Santaella, 2013).

De esta providencia se destaca la juridicidad de los daños derivados de limitaciones al derecho de propiedad; siempre y cuando no se trascienda el equilibrio de las cargas públicas (Pimiento, 2017a) y el hecho que permite computar el fin social y ecológico de la propiedad en el ejercicio indemnizatorio. En cuanto al contenido del derecho de propiedad, el fallo se aparta de la doctrina civilista clásica, pues define el contenido del derecho de propiedad en línea con el actual régimen constitucional. Esto no significa un absoluto ius utendi, fruendi y abutendi; sino una genérica utilidad privada de carácter económico (Santaella, 2013). No obstante, el umbral para que se dé una intervención de tipo expropiatorio es la vulneración del "núcleo esencial” del derecho de propiedad, lo que hace evidente la necesidad de precisar este concepto (Pimiento, 2017a), dadas las dificultades e incertidumbres que supone la determinación de cuál es el contenido básico de la institución dominical (Santaella, 2013).

Sin embargo, el fallo en comento al no ser contenido en una sentencia de unificación, no es aplicado de manera uniforme por todas las subsecciones de la Sección Tercera (Pimiento, 2017a) y aun adolece de un reconocimiento indemnizatorio o compensatorio a posteriori. Por otro lado, respecto de lo que aquí nos interesa, es decir, el amparo de derechos adquiridos de contenido patrimonial sujeto de afectación, no se trata de una jurisprudencia que los regule de manera expresa.

El marco legal en vigor podría ofrecer una luz para dar seguridad jurídica a posiciones subjetivas patrimoniales de índole minera y afectadas al interés general, mediante la caracterización de la minería como un servicio público. Autores clásicos del derecho minero, como el Profesor Eustorgio Sarria, definían el servicio público como una actividad que debe ser asegurada por los gobernantes, puesto que es indispensable para el desarrollo y no puede ser realizada completamente sin la intervención del Estado (Sarria, 1945). Además, 
concluían que no cabe duda de que la explotación de yacimientos representa una necesidad general (Sarria y Sarria Barraguén, 1979); asimismo que la importancia de dicha explotación, determinada por su utilidad económica y social, hace de la minería un servicio público (Sarria, 1945). El interés por caracterizar la actividad minera de esta manera consiste en que el Artículo 365 superior (Const., 1991, art. 365) establece que el Estado, por razones estratégicas o de utilidad social, podrá reservarse ciertas actividades; pero deberá indemnizar previamente al afectado.

Podría argumentarse que, al declarar una zona de conservación, el Estado se reserva una actividad estratégica de conservación, incompatible con la actividad minera lícita hasta ese punto, por lo que mediaría una indemnización previa. Esto permitiría no sólo remitirse al método usado para calcular el precio expropiatorio, que debe comprender el daño emergente y el lucro cesante (Pimiento, 2017b); sino contar con una indemnización previa, es decir, una remisión a un proceso de negociación como el que caracteriza la expropiación, más garantista con el propietario y menos oneroso para ambas partes — propietario y Estado — que acudir a los estrados judiciales. El sistema colombiano favorece una negociación voluntaria del precio con respecto a la expropiación forzosa, esto permitiría a las partes discutir de manera más equitativa las condiciones del mismo (Pimiento, 2017b) y tener en cuenta la afectación a la función ecológica o social.

\section{Conclusiones}

Para finalizar, se evidencia un incipiente desarrollo jurisprudencial que permite amparar la propiedad real en caso de afectaciones que incidan en el núcleo esencial de la misma, subordinándola al derecho colectivo y al medio ambiente. Este desarrollo es precario. Por un lado, se trata de una jurisprudencia que aún no está consolidada en el seno del Consejo de Estado y que plantea interrogantes importantes sobre el significado de expresiones clave como "núcleo esencial" del derecho de propiedad. Por otro lado, el desarrollo jurisprudencial actual no reconoce que en caso de afectaciones tengan un alcance expropiatorio o menos-, el pago de la indemnización o compensación sea previo. Así, se obliga al afectado a recurrir a la jurisdicción de lo contencioso administrativo para el reconocimiento de un derecho que es inherente a su título. Finalmente, claramente se trata de una jurisprudencia que estudia las afectaciones al derecho real. 
La cuestión del derecho de propiedad como un derecho amplio, que recae sobre bienes no reales, queda sin definición expresa. Lo anterior es preocupante, puesto que asistimos a una proliferación de medidas públicas que son fuertemente restrictivas de los atributos tradicionales de la titulación minera. Esto ya ha dado pie a reclamaciones de inversionistas extranjeros en sede de arbitraje internacional, con importantes implicaciones patrimoniales para el Estado. En este sentido, el hecho que el ordenamiento colombiano, ante una situación tan común como afectaciones con alcance expropiatorio, únicamente ofrezca la vía de lo contencioso administrativo al afectado, plantea interrogantes importantes bajo el principio de igualdad y bajo el principio de sostenibilidad fiscal.

Una violación del principio de igualdad se evidencia no solamente en la posibilidad que tiene el inversionista extranjero de acudir al arbitraje internacional, gracias a la regulación expresa de la expropiación indirecta en los tratados de inversión, posibilidad que no tiene el nacional; sino en la diferencia de procedimiento que el ordenamiento ofrece al titular expropiado y a aquél que es afectado, sea con efectos expropiatorios o menos. En el primer supuesto, la ley contempla una declaración de afectación que implica una indemnización previa, de manera que se trata de un trámite no litigioso, regulado por la ley y con alta seguridad jurídica para el propietario afectado. En el segundo supuesto, la indemnización se reconoce a posteriori, obligando por tanto al afectado a acudir al juez para el reconocimiento de un derecho que debería operar por el solo hecho de ser propietario o titular de un derecho adquirido. No debe olvidarse que el trámite previsto en la ley para la expropiación es una garantía del derecho de propiedad. No puede entenderse por qué razón dicha garantía no deba extenderse a afectaciones, máxime si tienen alcance expropiatorio.

Una violación del principio de sostenibilidad fiscal se evidencia en los grandes impactos que tiene sobre el fisco la litigiosidad que se impone para el reconocimiento de las indemnizaciones o compensaciones que apliquen ante una afectación. No sólo acudir a la jurisdicción contencioso administrativa implica una inversión de recursos estatales y del particular afectado; sino que, en el caso del inversionista extranjero, la falta de un marco de tipo legal incentiva recurrir al arbitraje inversionista-Estado. Lo anterior es especialmente evidente en el caso de afectaciones ya no a derechos reales; sino a derechos adquiridos, puesto que en este último supuesto la inseguridad jurídica en el ordenamiento colombiano es más marcada. 
Urge una intervención del legislador en la que se regulen garantías para titulares de derechos reales y de derechos adquiridos, de manera que sean previamente indemnizados o compensados en presencia de medidas que desarrollen el interés general en la protección del ambiente y que al hacerlo ocasionen daños o perjuicios. Una regulación de tipo legal permitiría no sólo darle más garantías de previsibilidad al titular del derecho; sino que permitiría una computación adecuada del interés general sobre el ambiente, los fines sociales y ecológicos de la propiedad constitucional, para desarrollar en la indemnización o compensación el interés general de los colombianos.

\section{Referencias bibliográficas}

Amaya Arias, A.M. (2017). Los derechos adquiridos frente a la protección del medio ambiente: análisis de dos casos puntuales. En O.D. Amaya Navas y A.M. Amaya Arias (Ed.), Derecho privado y medio ambiente, homenaje a Fernando Hinestrosa (pp. 53-91). Universidad Externado de Colombia.

Asamblea Departamental de Antioquia. (2019, 2 de septiembre). Ordenanza 31. Por medio de la cual se aprueba y se adopta el Plan de Ordenamiento Departamental de Antioquia - POD - "Construyendo nuestra casa común". http://www. asambleadeantioquia.gov.co/2016/index.php?option $=c o m \_j d o w n l o a d s \& v i e w=c a$ tegory\&catid $=64 \&$ ltemid $=854 \&$ limitstart $=30$

Blanco Rengifo, L. (2018). La regulación de la expropiación indirecta en los acuerdos bilaterales de inversión: Un privilegio a favor del inversor extranjero para la protección del derecho a la propiedad privada. Revista Foro del Jurista, (32), $174-228$.

Congreso de los Estados Unidos de Colombia. (1873, 26 de mayo). Ley 84. Código Civil de los Estados Unidos de Colombia. Diario oficial No. 2.867. http://www. secretariasenado.gov.co/senado/basedoc/codigo_civil.html

Congreso de la República de Colombia. (1989, 11 de enero). Ley 9. Por la cual se dictan normas sobre planes de desarrollo municipal, compraventa y expropiación de bienes y se dictan otras disposiciones. Diario oficial No. 38.650. https://www. funcionpublica.gov.co/eva/gestornormativo/norma.php?i=1175

Congreso de la República de Colombia. (2001, 15 de agosto). Ley 685. Código de Minas. Diario Oficial No. 44.545. http://www.secretariasenado.gov.co/senado/basedoc/ ley_0685_2001.html

Congreso de la República de Colombia. (2013, 22 de noviembre). Ley 1682. Por la cual se adoptan medidas y disposiciones para los proyectos de infraestructura de transporte y se conceden facultades extraordinarias. Diario Oficial No. 48.987. http://www. secretariasenado.gov.co/senado/basedoc/ley_1682_2013.html\#1

Consejo de Estado. (1999, 12 de agosto). Sentencia 5500 ( Juan Alberto Polo Figueroa, CP). http://legal.legis.com.co/document/Index?obra=jurcol\&document=jurcol_75 992041994af034e0430a010151f034

Consejo de Estado. (2005, 10 de agosto). Sentencia 1990.10957 (Ruth Stella Correa Palacio, CP). http://legal.legis.com.co/document/Index?obra=jurcol\& document=jurcol_2be7955903a54458a0c28bfa395b3f79 
Consejo de Estado. (2010, 3 de febrero). Sentencia 11001-03-26-000-2006-0005201(33187) (Enrique Gil Botero, CP). http://www.consejodeestado.gov.co/ busquedas/buscador-jurisprudencia/

Consejo de Estado. (2012, 9 de mayo). Sentencia 1993-04137 (Mauricio Fajardo Gómez, CP). http://legal.legis.com.co/document/Index?obra=jurcol\&document=jurcol_c4 1cb8ae5200000ae0430a010151000a

Constitución Política de Colombia. (1886). Gestor Normativo. https://www. funcionpublica.gov.co/eva/gestornormativo/norma.php?i=7153

Constitución Política de Colombia (1991). Avance Jurídico. http://www.secretariasenado. gov.co/senado/basedoc/constitucion_politica_1991.html

Corte Constitucional. (1997, 13 de agosto). Sentencia C-374. (José Gregorio Hernández Galindo, MP). https://www.urosario.edu.co/observatorio-de-lavado-de-activos/ Archivos/C-374-97.pdf

Corte Constitucional. (1995, 20 de abril). Sentencia C-168. (Carlos Gaviria Díaz, MP). http://www.corteconstitucional.gov.co/relatoria/1995/C-168-95.htm

Corte Constitucional. (2009, 1 de abril). Sentencia C-242. (Mauricio González Cuervo, MP). http://www.corteconstitucional.gov.co/relatoria/2009/C-242-09.htm

Corte Constitucional. (2010, 1 de diciembre). Sentencia C-983. (Luis Ernesto Vargas Silva, MP). http://www.corteconstitucional.gov.co/RELATORIA/2010/C-983-10.htm

Corte Constitucional. (2011, 30 de marzo). Sentencia C-227. (Juan Carlos Henao Pérez, MP). http://www.corteconstitucional.gov.co/RELATORIA/2011/C-227-11.htm

Corte Constitucional. (2016, 8 de febrero). Sentencia C-035. (Gloria Stella Ortiz Delgado, MP). http://www.corteconstitucional.gov.co/relatoria/2016/c-035-16.htm

Corte Constitucional. (2017, 15 de mayo). Sentencia T-325 (Aquiles Arrieta Gómez, MP). https://www.corteconstitucional.gov.co/relatoria/2017/T-325-17.htm

Corte Constitucional. (2017, 30 de mayo). Sentencia T-361 (Alberto Rojas Ríos, MP). http://www.corteconstitucional.gov.co/relatoria/2017/t-361-17.htm

El Presidente de la República de Colombia. (1984, 2 de enero). Decreto 1. Por el cual se reforma el Código Contencioso Administrativo. Diario Oficial No. 36.439. http://www.secretariasenado.gov.co/senado/basedoc/codigo_contencioso_ administrativo.html

Herrera Robles, A. (2002). Los derechos adquiridos frente a la función administrativa. Revista de Derecho, (18), 106-117.

Hernández Betancur, L.F. (2017). Nuevas Dimensiones de la causa expropiandi en Colombia: El interés nacional y estratégico como dinamizador del cambio en los regímenes especiales de expropiación. En J. Pimiento Echeverri y H. Santaella Quintero (Eds.), La expropiación forzosa en América y Europa (pp. 161-229). Universidad Externado de Colombia.

Luna Gélvez, M.A. y Correa Sánchez, N., (2015). Inexistencia de derechos adquiridos: Títulos mineros vigentes en áreas posteriormente declaradas excluibles de minería. Revista de Derecho Público, (34), 4 - 30. http://dx.doi.org/10.15425/ redepub.34.2015.31

Ministerios de Ambiente y Desarrollo Sostenible (2014, 19 de diciembre). Resolución 2090. Por medio de la cual se delimita el Páramo Jurisdicciones - Santurbán - Berlín, y se adoptan otras determinaciones. Diario Oficial 49.373. https:// redjusticiaambientalcolombia.files.wordpress.com/2016/03/res_2090_2014santurban.pdf 
Pimiento Echeverri, J.A. (2015). Derecho Administrativo de Bienes. Los bienes públicos: historia, clasificación, régimen jurídico. Universidad Externado de Colombia.

Pimiento Echeverri, J.A. (2016). Patrimonio natural y cultural. Aportes para la construcción de un concepto común en su relación con el derecho de propiedad. Revista de Derecho Administrativo Económico, (23), 23 - 39. https://doi. org/10.7764/redae.23.2

Pimiento Echeverri, J.A. (2017a). La responsabilidad del Estado por limitaciones ambientales a la propiedad privada. En O.D. Amaya Navas y A.M. Amaya Arias (Eds.), Derecho privado y medio ambiente, homenaje a Fernando Hinestrosa (pp. 333-374). Universidad Externado de Colombia.

Pimiento Echeverri, J.A. (2017b). La expropiación en el derecho colombiano actual. Reflexiones sobre una institución en constante transformación. En J. Pimiento Echeverri y H. Santaella Quintero. (Eds.), La expropiación forzosa en América y Europa (pp. 121-159). Universidad Externado de Colombia.

Quintero, F. (31 de marzo de 2014). Delimitación de Santurbán, precedente histórico para otros 33 páramos. El tiempo. https://www.eltiempo.com/archivo/documento/ CMS-13760895

Santaella Quintero, H. (2013). Responsabilidad patrimonial del estado por afectaciones ambientales a la propiedad privada. En A.F. Ospina Garzón (Ed.), Los grandes fallos de la jurisprudencia administrativa colombiana (pp. 243-254). Universidad Externado de Colombia.

Santaella Quintero, H. (2017). El régimen constitucional de la expropiación en Colombia. En J. Pimiento Echeverri y H. Santaella Quintero (Ed.), La expropiación forzosa en América y Europa (pp. 58-117). Universidad Externado de Colombia.

Santos Rodríguez, J.E. (2016). Naturaleza y formación de la concesión minera. En J.C. Henao y M.F. Montoya Pardo (Eds.), Minería y Desarrollo. Tomo I: Aspectos jurídicos de la actividad minera (pp. 61-86). Universidad Externado de Colombia.

Sarria, E. (1945). Régimen jurídico de la industria minera. Revista de la Universidad Nacional, (4), 121-143.

Sarria, E. y Sarria Barraguen, M. (1979). Derecho de Minas, Régimen Jurídico del Subsuelo. Ediciones Rosaristas.

Tratado de Libre Comercio entre Colombia y Canadá. (2011). Organización de los Estados Americanos, Sistema de Información sobre Comercio Exterior. http://www. sice.oas.org/TPD/AND_CAN/Final_Texts_CAN_COL_s/Index_s.asp

Tribunal Administrativo de Santander. (15 de mayo de 2020). Exp.6800123330002015-00734-00 (Solange Blanco Villamizar, MP). https://www.ramajudicial. gov.co/documents/2209728/34203550/Auto + tutela + 2015-0073400+Santurb\%C3\%A1n..pdf/874a11cc-fe7a-4df5-b2ef-aa713a0efaca 